\title{
NUMERICAL DEVELOPMENT OF A STRENGTHENED WALL-TO-DIAPHRAGM SEISMIC CONNECTION: CALIBRATION AND APPLICATION ON A BUILDING PROTOTYPE
}

\author{
FABIO SOLARINO ${ }^{1,2^{*}}$, DANIEL V. OLIVEIRA ${ }^{1}$ AND LINDA GIRESINI $^{2}$ \\ ${ }^{1}$ ISISE, Institute of Science and Innovation for Bio-Sustainability (IB-S) \\ Department of Civil Engineering, University of Minho \\ Campus de Azurém, 4800-058, Guimarães, Portugal \\ e-mail: solarino.fabio@gmail.com, www.hms.civil.uminho.pt/ (*corresponding author) \\ ${ }^{2}$ Department of Energy, Systems, Territory and Constructions Engineering (DESTEC) \\ University of Pisa \\ Largo Lucio Lazzarino, 1, 56126, Pisa (PI) Italy \\ e-mail: linda.giresini@unipi.it, www.destec.unipi.it/
}

Keywords: Wall-to-floor connections, URM buildings, Numerical calibration, Nonlinear dynamic analyses, timber floors.

\begin{abstract}
Effective wall-to-floor connections are crucial components of historical buildings to avoid dangerous mechanisms under seismic actions. Existing buildings often present poor friction-based links between timber floor and masonry wall and are not able to ensure the socalled "box behavior", necessary for the correct distribution of seismic forces.

Nonlinear static analysis is one of the most common tools for the seismic assessment of unreinforced masonry buildings considering advanced nonlinear materials description and allowing for different approaches. The selection of a proper control node, for the definition of the pushover curve, is fundamental and sometimes controversial. Moreover, connections are modelled as simply fixed or absent at all. Dynamic nonlinear analysis seems preferable even suffering from a higher computational effort.

On the bases of previous experimental campaign developed at the University of Minho, the pullout behavior of a strengthened and unstrengthened masonry-to-timber connection was simulated numerically using OpenSees software. The connection model considers strength degradation and pinching, in agreement with the experimental behavior, and is validated from the energetic point of view, suitable for being included in a global finite element model to study the influence of the hysteretic energy dissipated within the connections on the overall seismic response.
\end{abstract}

This paper describes the calibration process and the application of the connection model into a unreinforced masonry prototype using nonlinear dynamic analysis under real seismic inputs. Both strengthened and unstrengthened configurations are implemented and results compared. The selected model is part of the blind prediction competition organised within the SERA-AIMS project involving the shaking table test of a half-scaled aggregate. 
The main numerical outcomes show that the model is capable to predict typical damage in masonry buildings. The presence of a strengthened wall-diaphragm solution seems to play a secondary role in the overall seismic capacity of the aggregate, probably due to the peculiarity of the building layout, while the absence of the floor can lead to premature damages.

\section{INTRODUCTION}

The seismic response of Unreinforced Masonry (URM) buildings is generally weak, mainly due to their intrinsic high inertial forces, but simple and effective characteristics make the structure able to sustain even medium-high intensity ground motions [1]. Despite the geometrical regularities, quality of the materials, masons' expertise play an important role in the capacity of the structure, connections between the walls and between vertical and horizontal elements are crucial for the proper distribution of seismic forces and for preventing dangerous local mechanisms [2].

Finite Element (FE) analysis using homogeneous masonry elements is widely used for seismic assessment of historical structures in spite of unavoidable uncertainties concerning material properties, boundary conditions, value of damping and additional modeling hypothesis $[3,4]$. Commonly, simplified equivalent-frame, macro-model approaches under nonlinear-static analyses are addressed for the evaluation of the seismic capacity of global structures [5-7],

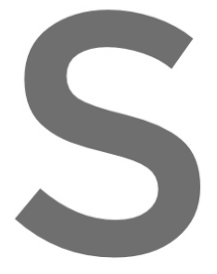
while kinematic analys and relatively quicl ts dynamic nonlinear of local mechanisins $[11,12]$.

Whatever modeling/analy sis approach is tak
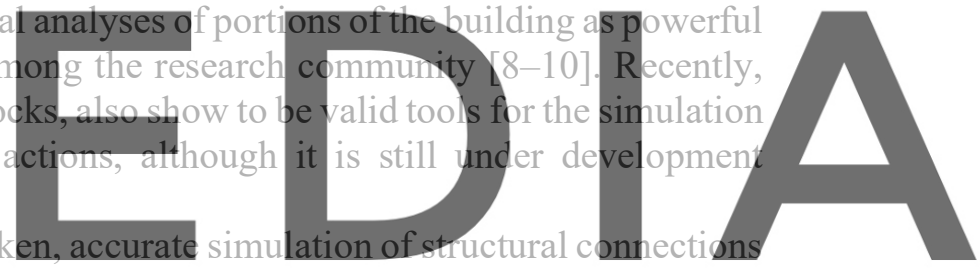

is crucial for the seismic global and local capacity, as it highly influences the dynamic

the quality/degradation of existing links. Weak WD links may lead to complex interactions concerning frictions or local crushing of masonry, involving possible collapse of the horizontal or/end vertical elements. Strengthened solutions usually comprises metallic components providing a more resistant and ductile behavior [13]. The hysteretic energy of such connections partially influences the overall energy dissipated by the building under seismic forces and should be accounted for in the numerical model. Unfortunately, the experimental knowledge about the force-displacement diagram of these connections is poor and it is difficult to reproduce complicated hysteresis using common modeling techniques. Moreover, WD connections include a large variety of details resulting in several different configurations, hardly to standardize [13].

Recently, Moreira [14] investigated the seismic behavior of rubble stone masonry wall to timber floor beam connections through experimental pull-out tests in both strengthened and unstrengthened specimens (Figure 1), focusing on the monotonic and cyclic tensile behavior. The reinforced connection was seen to be promising for the seismic improvement of existing buildings, often presenting poor friction-based links. This study is considered here as the base for the numerical calibration and validation of the connection model. The monotonic tests of 
the unstrengthened connection are useful in order to give an idea of their poor capacity in terms of strength and ultimate displacement, setting the conditions for possible numerical simulations.
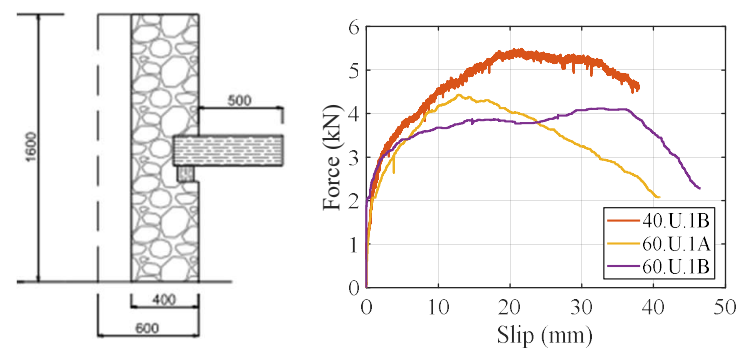

(a)
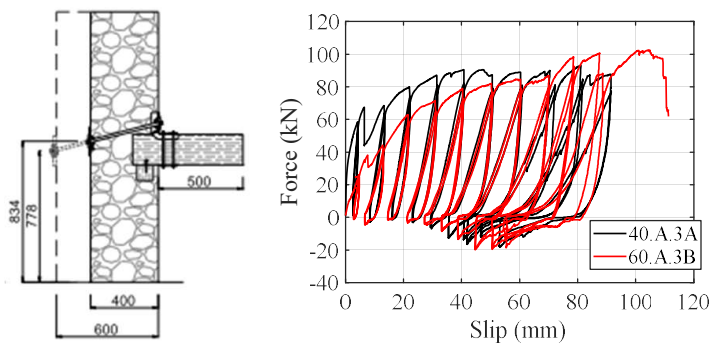

(b)

Figure 1: Pull-out tests on WD connections performed by Moreira [147; (a) unstrengthened; (b) strengthened configuration

While kinematic or rocking approaches allow to include WD connections through simple multi-linear constitutive laws, examples on modeling hysteretical structural connections calibrated on experimental bases can be found for instance in [15-17] developed for connections in Cross Laminated Timber (CLT) members. Moreover, no similar work has been done so far on historical building wall-floor joints. Accurate FEmodels of the connections are also possible, but not reconmended on global buildings with large number of degrees of freedom where the

On the base of $t$ versatile model of reproducing the axial
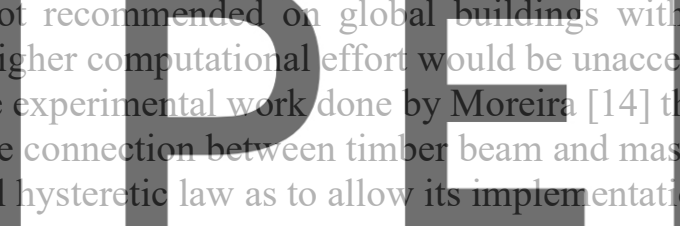

\section{CALIBRATION OF CONNECTION MODEL}

evaluation and design of the connection, appropriate path towards the retrofitting of existing buildings under performance- or force-based nonlinear approaches $[18,19]$. ASCE [20] allows to use cyclic mathematical model when nonlinear dynamic procedures require additional hysteretic parameters and if shape of the experimental hysteresis loop and hysteretic energy is in reasonable agreement with the modelled ones.

Two different types of connections are modeled and calibrated to fit monotonic and hysteretic experimental curves: (i) unstrengthened connection; (ii) strengthened connection. The experimental force-displacement curves, shown in Figure 1, were obtained for different wall thickness and vertical stress levels in order to study the influence of two floor levels. Whilst reinforced connections were tested under both monotonic and cyclic procedures, only monotonic experimental curves are available for unstrengthened configurations. Thus, some hypotheses had to be made about the unloading/reloading shape of the hysteresis curve.

Although the experimental campaign cannot be statistically representative of WD joints, common trend was observed among the typology of connections. In addition, despite the strength capacity significantly increases with reinforcement (about 10 times) when comparing the un-reinforced specimen, the influence of different floor level seems less visible on the 
strength, ultimate displacement capacity and shape of hysteretic curves.

Table 1: Summary of experimental tests developed by Moreira [14]; test are labelled using the following criterium: TT.R.NL, where TT is the wall thickness, $\mathrm{R}$ is the type of connection ( $\mathrm{U}=$ unreinforced or $\mathrm{A}=$ reinforced), $\mathrm{N}$ is the number of the wall and $\mathrm{L}$ the location of the connection within the wall

\begin{tabular}{|c|c|c|c|c|c|}
\hline floor level & stress level & wall thickness & connection type & monotonic & cyclic \\
\hline \multirow[b]{2}{*}{ Upper Level } & \multirow[b]{2}{*}{$0.2 \mathrm{MPa}$} & \multirow[b]{2}{*}{$40 \mathrm{~cm}$} & unstrengthened & $\begin{array}{l}\text { 40.U.1A } \\
\text { 40.U.1B }\end{array}$ & - \\
\hline & & & strengthened & 40.A.1A & $\begin{array}{l}\text { 40.A.3A } \\
\text { 40.A.4A } \\
\text { 40.A.4B }\end{array}$ \\
\hline \multirow[b]{2}{*}{ Lower Level } & \multirow[b]{2}{*}{$0.4 \mathrm{MPa}$} & \multirow[b]{2}{*}{$60 \mathrm{~cm}$} & unstrengthened & $\begin{array}{l}60 . \mathrm{U} .1 \mathrm{~A} \\
60 . \mathrm{U} .1 \mathrm{~B} \\
\end{array}$ & - \\
\hline & & & strengthened & 60.A.1A & $\begin{array}{l}\text { 60.A.2B } \\
60 \cdot A \cdot 3 \mathrm{~A} \\
60 . \mathrm{A} \cdot 3 \mathrm{~B}\end{array}$ \\
\hline
\end{tabular}

On the base of these considerations, the WD unreinforced connection model is intended to be calibrated based on three monotonic tests (40.U.1B, 60.U.1A, 60.U.1B), while 60.A.3B is selected as the benchmark test for the reinforced connection model, the only one pulled out up to full collapse of the connection (Figure 1).

Within the aim of this work, a single axial spring-like element, calibrated to simulate the overall behavior between the timber floor beam and the masonry wall, is intended to be modelled in a FE environment easy to be implemented in global models. Current experimental tests did not take into account pounding and shear effect, necessary for the coupled axial-shear $W$ tensile tests. Therefore, adequate hypotheses have to be developed by the analyst a remaining unknowns. Inelastic uniaxial material is assigned to a zeroLength element [21], representing a two-node spring simply fixed at one end and free to translate to the second end

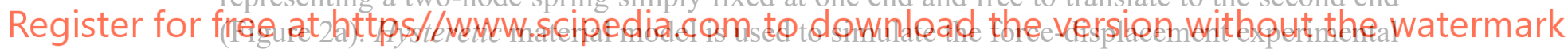
cycles (Figure 2b), accounting for pinching of force and deformation, damage due to deformation and energy, and degraded unloading stiffness based on ductility. The envelope is defined based on three points in each direction and 5 additional parameters governing the cyclic degradation and shape of the curve.

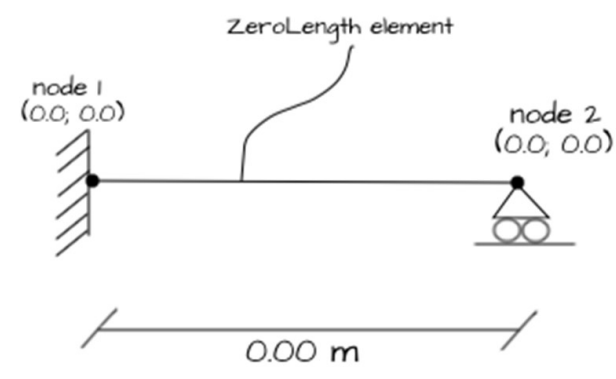

(a)

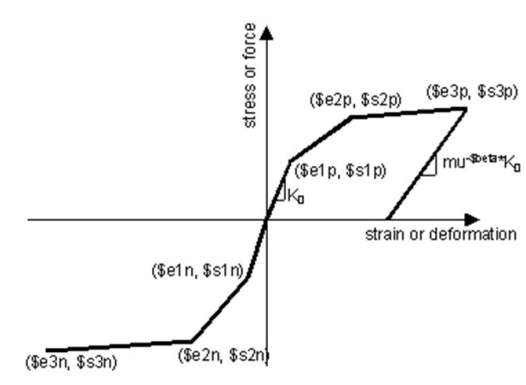

(b)

Figure 2: 1-D connection model developed in OpenSees [22]; (a) model layout; (b) definition of Hysteretic material model envelop points 
Numerical envelops sufficiently fit the experimental monotonic averaged curves in the case of unstrengthened connections and the backbone curve for the 60.A.3B strengthened configuration (Figure 3). It is worth noting that experimental behavior clearly presents a nonelastic unloading path (i.e. unloading slope is almost vertical if compared to the pre-yielding path, see Figure $1 \mathrm{~b}$ ), while numerical unloading is basically elastic ( $K_{\text {unload }}=K_{0}$, for zero unloading degradation). According to the above consideration, the first yielding point P1 with coordinates $\left(\varepsilon_{1}, \sigma_{1}\right)$, not only defines the elastic limit, but also influences the unloading stiffness, so that two additional points can be devoted to the shape of the envelop curve. While in tension, it is possible to define a very low residual stress, $\sigma_{3}$, simulating the collapse of the connection, indefinitely elastic behavior can be set in compression reproducing the relatively rigid pounding of the beam over the masonry panel. Comparison between the experimental and numerical 60.A.3B hysteresis is shown in Figure 4a, demonstrating sufficient agreement in terms of loading/unloading/reloading paths, ultimate capacity, energy computation (Figure 4b).

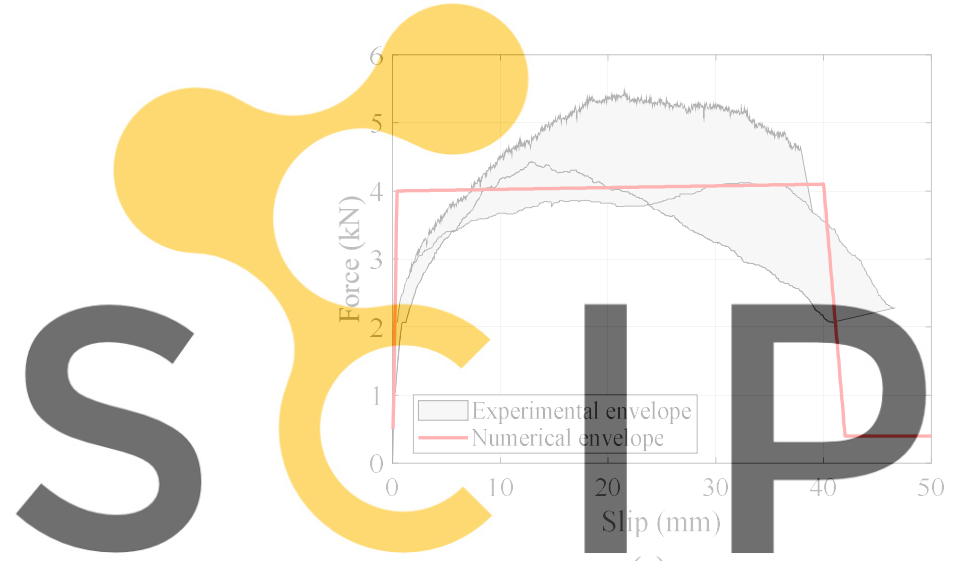

(a)

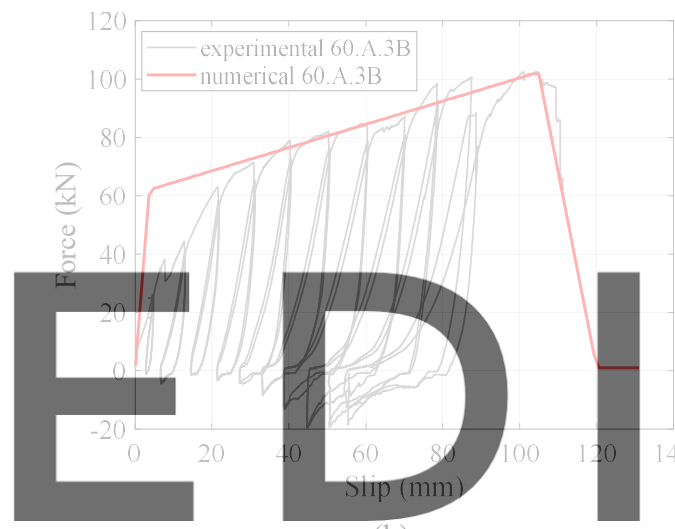

(b)

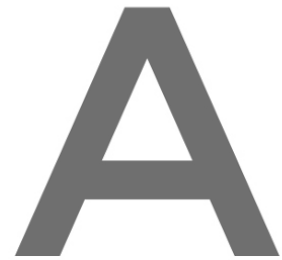

Register for 3: Comparison between numerical and experimental envedope curves of (a) unstrengthened,

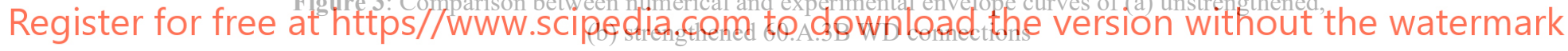

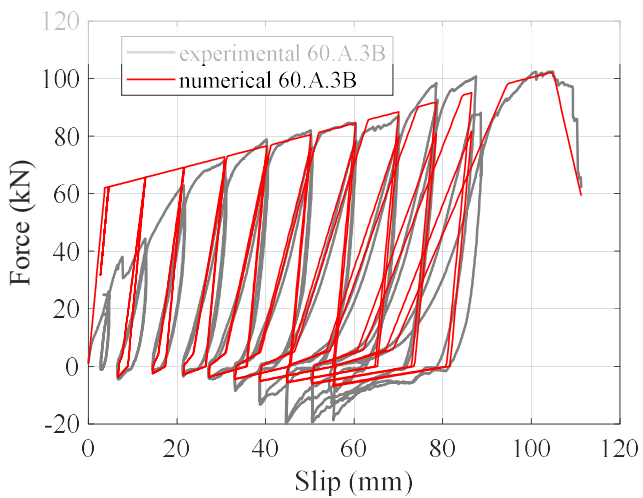

(a)

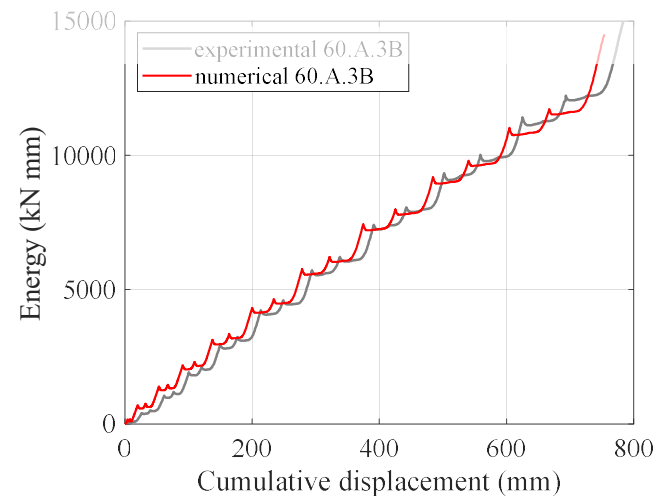

(b)

Figure 4: Comparison between numerical and experimental connections (a) 60.A.3B strengthened force-slip curve; (b) total energy

The connections are subjected to reverse cyclic loads to better show the capability of the 
model when inverting displacement sign (Figure 5). Only few parameters are necessary to define damage and pinching into the hysteretic model which agrees well with the selected experimental connections. Moreover, despite it is not possible to study the influence of each connection component, setting a limit of the approach, the same calibration procedure can be easily adopted to similar connections, simply modifying few parameters.
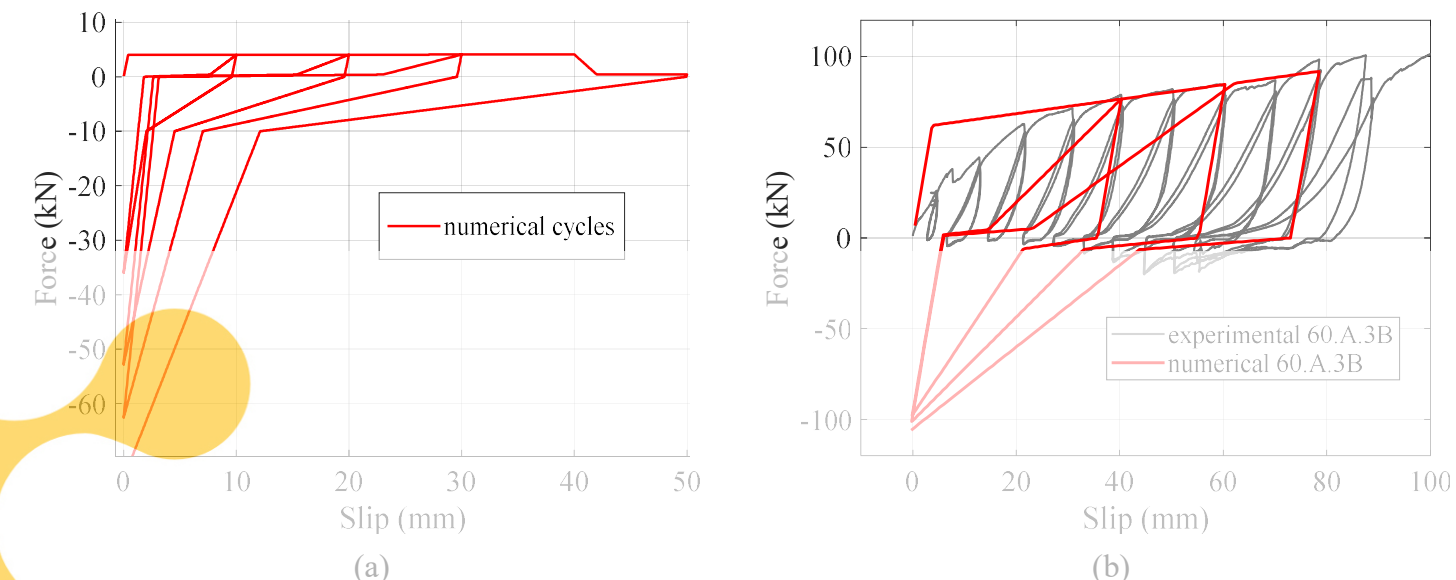

(b)
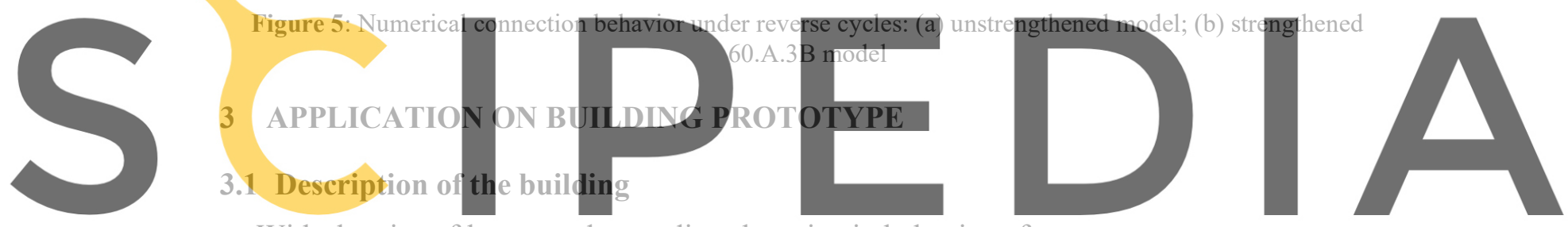

With the aim of better understanding the seismic behavior of stone masonry aggregates, a

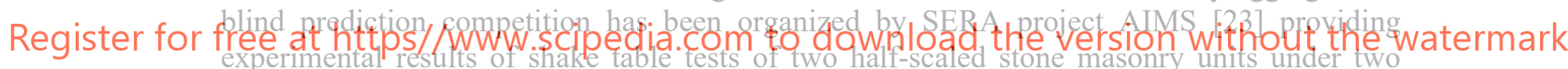
components of horizontal excitations. Research community was invited to develop advanced numerical strategies able to predict the seismic damage of such structures. The geometry is based on typical aggregate layout (Figure 6a), where Unit 1 is a $30 \mathrm{~cm}$ thick $2.20 \mathrm{~m}$ tall single floor U-shape building, while Unit 2 is a two floor $3.15 \mathrm{~m}$ tall rectangular building with decreasing thickness along the height $(35 \mathrm{~cm}$ at the ground floor and $25 \mathrm{~cm}$ at the top floor). Timber beams follow two different orientations and form a relatively weak WD connection, as they are simply infixed and supported into the masonry wall (Figure 6c). Steel angles placed to anchor beams into walls are only present as precaution for later phases of the test and are not activated, thus not expected to influence the behavior of the test buildings. $2 \mathrm{~cm}$ thick wooden planks are placed perpendicular to the beams composing a flexible diaphragm. Unit 2 shares one façade with Unit 1; the discontinuity is given by a dry joint connection among the two buildings. A series of $6 \mathrm{~cm}$ thick timber lintels are placed above the openings, and reduction of thickness below the openings is considered by using $15 \mathrm{~cm}$ thick spandrels. The structure presents symmetry along the Y longitudinal axis. 


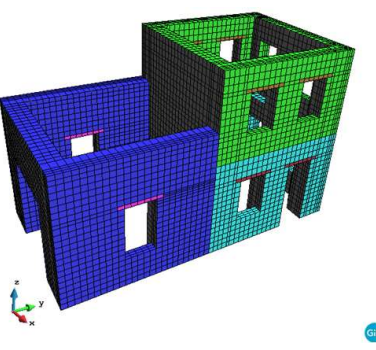

(a)

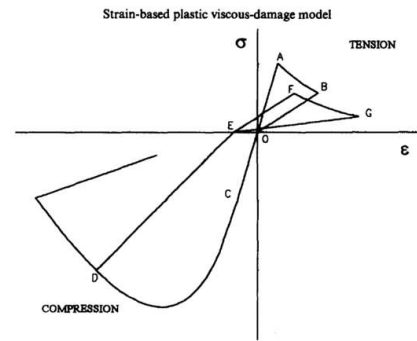

(b)

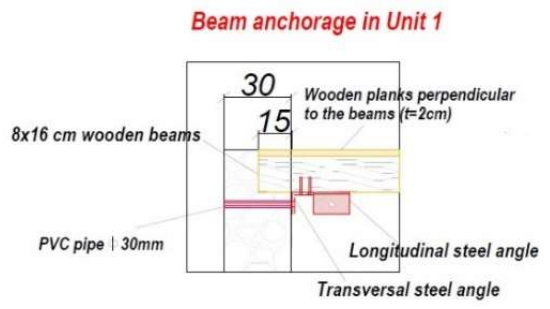

(c)

Figure 6: (a) 3D FE model- timber beams are not shown for the sake of clarity; (b) masonry material model adopted; (c) detail of WD connection

\subsection{Numerical model}

3D numerical simulation of the aggregate is performed in OpenSees v.3.0.3 FE framework [22] following a macro-modeling approach where homogeneous masonry material properties need to be assumed. stBrick elements (eight-node brick object) have been used for masonry and timber lintels, while trusses are adopted for timber beams. The model counts 16688 elements and 22672 nodes, for a total of 66016 degrees of freedom (D.O.F.) (Figure 6a). Two models are developed in order to study the influence of WD connections, namely unreinforced and reinforced connection models. The former is supposed to be the most representative of the

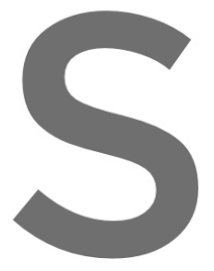
actual behavior of ex] solution in agreement with the masonry material model assigned to the brick [24], originally developed for concrete and strength enhancement for confinement, and (Figure 6b). The material was implemented in OpenSees by 'T

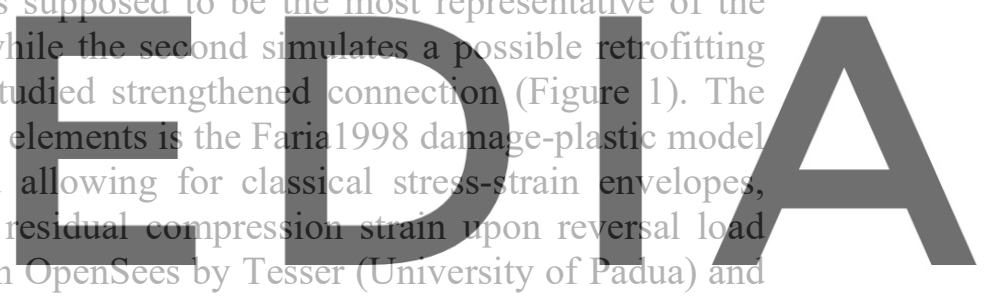
Talledo (University of Venice), who kindly shared the corresponding routine. Selected masonry

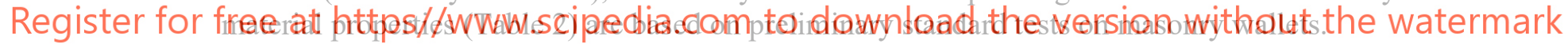

Table 2: Faria1998 material properties

\begin{tabular}{cccc}
\hline Young's modulus & $E$ & $2.0 e 6$ & $k P a$ \\
\hline Poisson's ratio & $v$ & 0.14 & - \\
\hline Compressive strength & $f_{c}$ & 1300 & $k P a$ \\
\hline Tensile strength & $f_{t}$ & 170 & $k P a$ \\
\hline Damage parameter in compression & $A_{n}$ & 2.0 & - \\
\hline Damage parameter in compression & $B_{n}$ & 0.7 & - \\
\hline Damage parameter in tension & $A_{p}$ & 1.0 & - \\
\hline Plastic deformation coefficient & $\beta$ & 0.4 & - \\
\hline
\end{tabular}

zeroLengthImpact $3 D$ [25] elements were used at the interface between the units capable of reproducing pounding/impact, and friction between the walls, based on Hertz and Coulomb theories, respectively. Values of 0.6 friction ratio and 0.0 cohesion were selected as reasonable value for dry stones [26-28]. Previously calibrated Hysteretic material is assigned to zeroLengthElement (Section 2), simple node-to-node uniaxial springs between trusses and walls, while shear D.O.F. are assumed rigid. Timber beams are modelled using two-nodes truss 
elements and floor mass is lamped at the beam ends. Base nodes are fixed. The model is meshed following a structured mesh of elements with characteristic length of 5 or $10 \mathrm{~cm}$ (Figure $6 \mathrm{a}$ ).

\subsection{Analysis and results}

After the application of self-weight, the transient analysis is set using Newmark's integrator, Newton algorithm, energy increments-based convergence test and tolerance of 1e-3 with 100 maximum number of iterations. Damping matrix is specified using Rayleigh damping [29] as a linear combination of stiffness and mass-proportional damping matrices, common in FE dynamic analyses, setting $\alpha_{M}=3.9685, \beta_{K}=0.0001897$ calculated based on $1^{\text {st }}$ and $10^{\text {th }}$ eigenfrequencies in order to account for all important translational and torsional modes and selecting a value of damping ratio of $\xi=3 \%$. It is worth noting that the eigenvalue analysis was performed disconnecting the two units and neglecting floor trusses, in order to evaluate a wide range of reasonable mode shapes.

The model is subjected to two horizontal components of the Montenegro 1979 real record [30], scaled and adapted for the shaking table limits. An Incremental Dynamic Analysis (IDA) is planned considering 25\% - 50\% - 75\% and 100\% of the ground motion, reaching the maximum PGA of the shake table $(0.875 \mathrm{~g})$. According to preliminary analyses, a reduced timehistory is performed neglecting the initial $25 \%$ sequence, considered to insignificantly damage the structure, thus not justifying the increased computational time. Each level comprises a
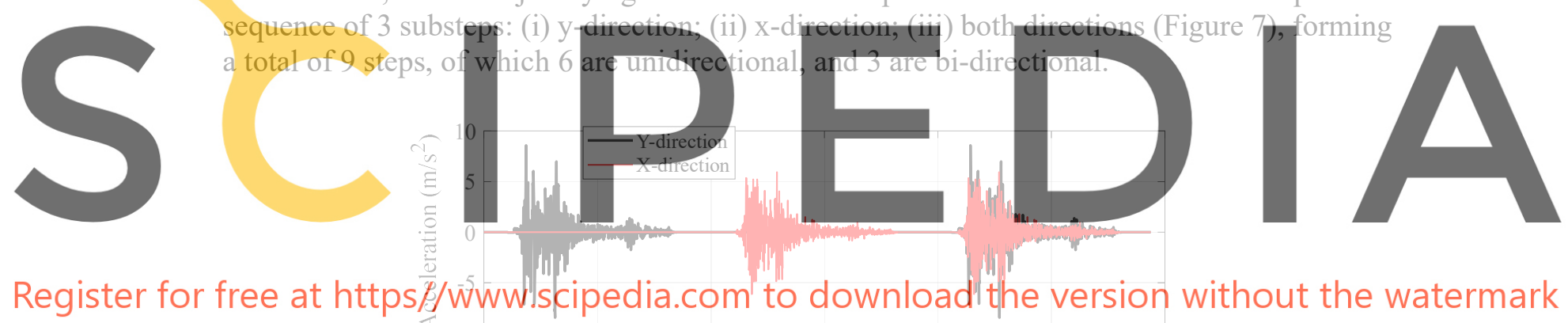

Register for free at https $/{ }^{-5}$ wwll scipedia.com to download the version without the watermark

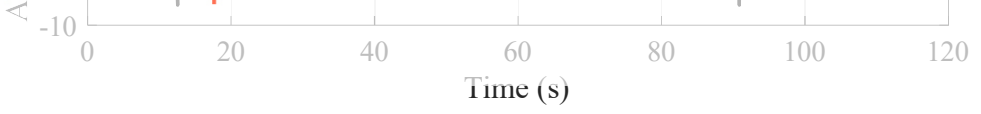

Figure 7: 100\% sequence of Montenegro 1979 input ground motion: [Y - X - XY]

Total computational time necessary for the whole sequence (49,844 steps) was about 5 days 13 hours using a Windows-based machine with intel Core i7-9750H CPU $(2.60 \mathrm{GHz})$, and $16 \mathrm{~Gb}$ RAM. Damaged models are shown in Figure 8 in terms of principal tensile strains, while time-history results are displayed in Figure 9 in terms of top floor displacements and seismic coefficient, calculated as $\alpha_{i}=\sum F_{i} / W$, where $i$ stands for $\mathrm{X}$ or $\mathrm{Y}$ directions and $W$ is the selfweight of the structure.

Peak displacements are attained at the last bi-directional step of the $100 \%$ sequence. Here, the maximum horizontal displacements in Y-direction at the top corner of unit 2 (46 $\mathrm{mm}$ in the strengthened specimen and $35 \mathrm{~mm}$ for the unstrengthened model) are about 5 times higher than the displacement under 100\% Y (Figure 9). Very few differences can be observed between the unstrengthened connection model and the strengthened one, both in terms of damage and displacements. 


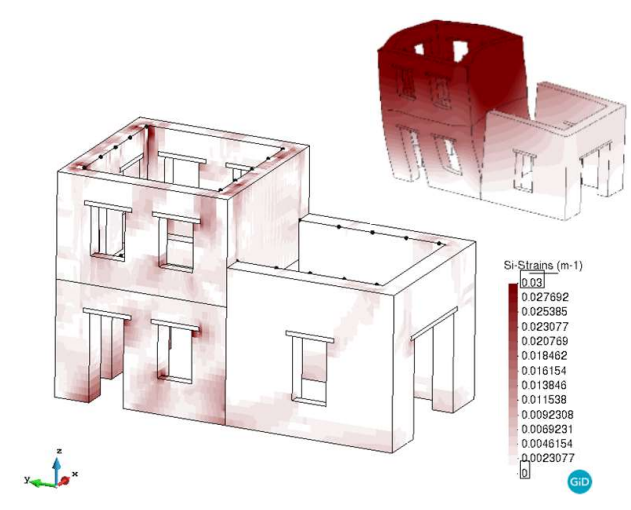

(a)

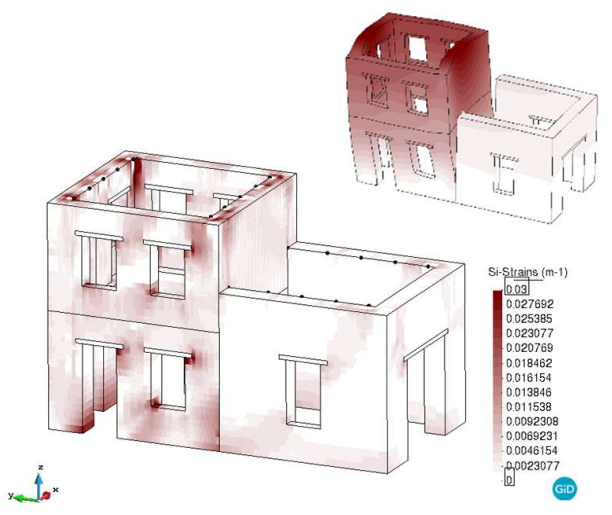

(b)

Figure 8: Tensile principal strains; (a) unreinforced model; (b) reinforced model

The maximum relative beam-wall detachment (calculated as the difference of the beam end and the wall node displacements) is attained in the unstrengthened model without exceeding $1 \mathrm{~mm}$. This is quite a low value, deserving further analysis.
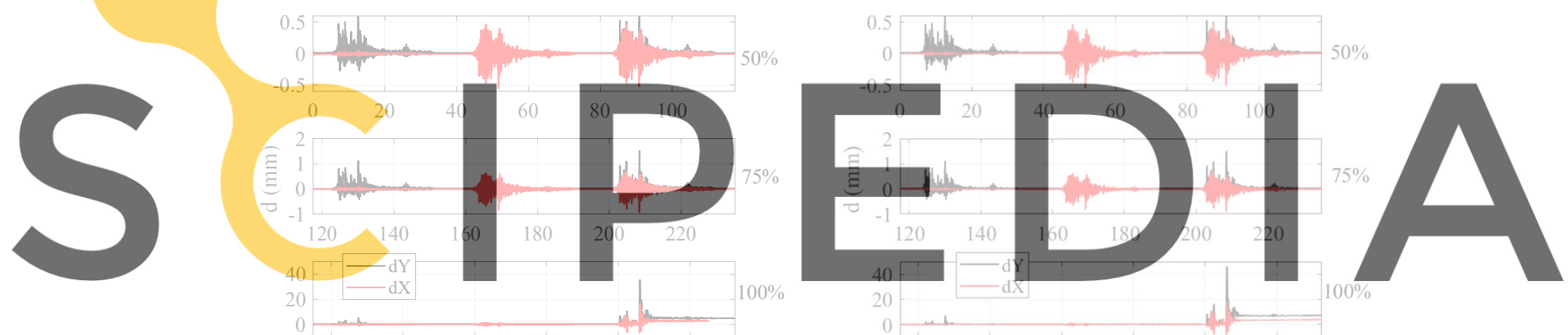

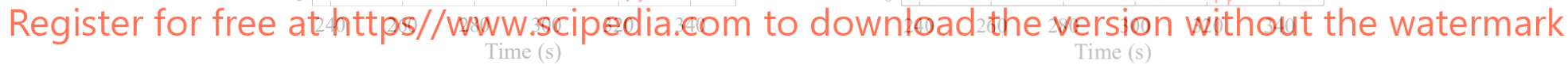

Top floor corner unit 2 time-history displacements along $\mathrm{Y}$ and $\mathrm{X}$ directions
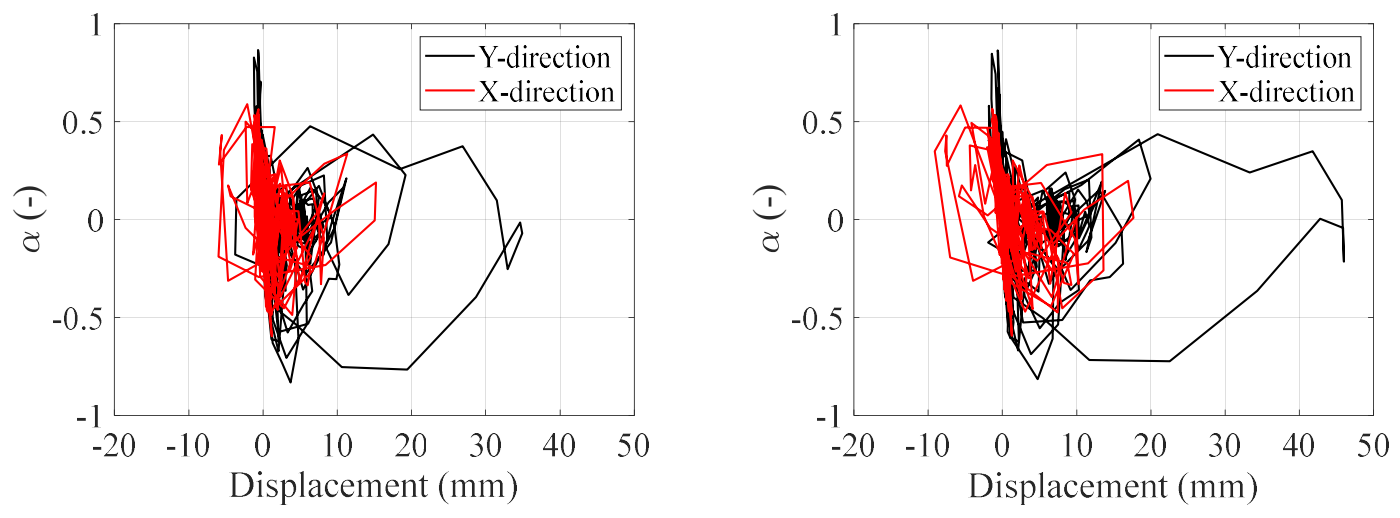

Seismic coefficient vs. horizontal $\mathrm{X}$ and $\mathrm{Y}$ displacements at the top unit 2 corner

(a)

(b)

Figure 9: Dynamic nonlinear analysis results; (a) unreinforced model; (b) reinforced model 
Time history analysis results of same model neglecting timber beams (floor mass is lamped over the wall nodes) are shown in Figure 10 for comparison, demonstrating that buildings with no diaphragm attain higher displacement levels and damages. Compared to the previous models, the building with no floors is expected to be severely damaged since the $100 \% \mathrm{Y}$ substep, where local and global mechanisms could be activated.

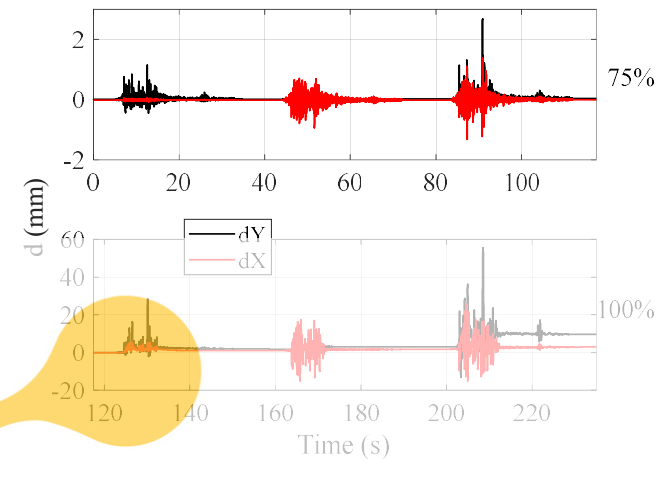

(a)

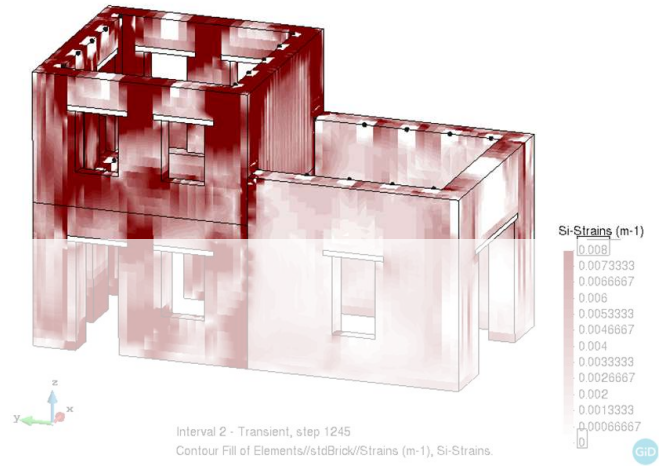

(b)

Figure 10: No-diaphragm model results: (a) displacement time-history of $75 \%$ and 100\% sequence; (b) tensile
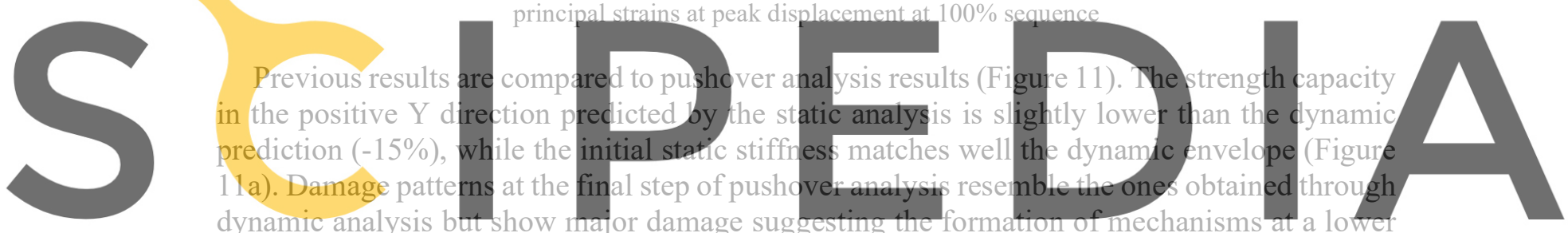

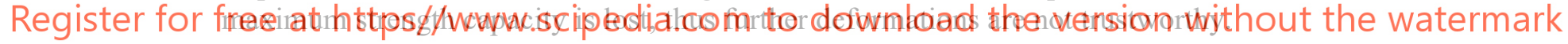

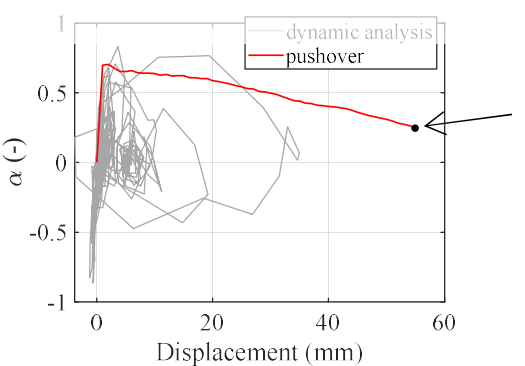

(a)

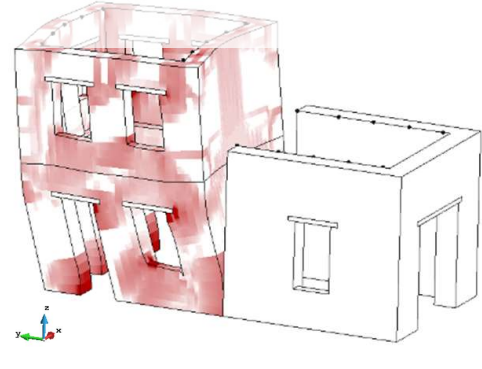

(b)

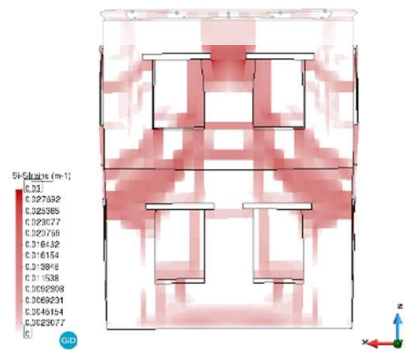

Figure 11: Static nonlinear analysis results: (a) comparison between static and dynamic capacity curves; (b) principal tensile strains and deformed shape at final step 


\section{CONCLUSIONS}

Nonlinear dynamic time-history analysis is considered one of the most advanced techniques for evaluating the influence of hysteretic wall-to-diaphragm connections on a global URM building in a finite element environment. This work aimed at developing a relatively simple nonlinear numerical connection simulating the complex axial behavior between timber and masonry at floor level. Such connection models are ready to be used in global building models in order to study the influence in a reinforcement perspective.

Two long incremental dynamic analyses were performed on a building prototype, within the scope of a blind prediction competition, in order to predict the behavior of typical aggregate under shake table tests. In-plane and out-of-plane damage is expected especially under the last $100 \%$ bidirectional quake, where the model attains the peak deformation of more than $40 \mathrm{~mm}$. No visible improvement is obtained if wall-diaphragm model simulating a strengthened solution is set, probably due to the peculiarity of the buildings and relatively low floors. Local damages are expected especially on Unit 2 façades normal to Y-axis, due to the flexibility of the floor, and bouncing effect at the interface with Unit 1 . The same façades are expected to rock out-of-plane, because of the formation of vertical cracks at the connection with transversal walls (Figure 8).

The presence of Unit 1 makes the aggregate more flexible in the positive $\mathrm{Y}$-direction, where the peak displacement is attained (Figure 9). Moreover, unit 2 - ground floor masonry piers are expected to rock along Y-direction, leading to a possible "soft-story" collapse.

The absence of timber floor beams results in a heavily damaged model where premature local mechanisms are expected to appear, demonstrating the well-known importance of adequate horizontal diaphragms.

Finally, a nonlinear static (pushover) analysis was performed and compared to dynamic analysis results only for the unreinforced connection model. The pushover curve agrees well with the dynamic analysis in terms of initial stiffness and strength capacity (being this about $15 \%$ lower than the seismic coefficient obtained from dynamic analysis). However, the pushover analysis tends to overestimate the ultimate displacement capacity of about $60 \%$ with respect to the dynamic analysis, even if severe damages are expected rather before.

Acknowledgements. This work was partly financed by FEDER funds through the Operational Programme Competitiveness Factors (COMPETE) and by national funds through the Foundation for Science and Technology (FCT) within the scope of project POCI-01-0145FEDER-007633. The financial support of FCT to the first author, through the PhD grant $\mathrm{SFRH} / \mathrm{bd} / 131652 / 217$, is also acknowledged. This work could not be possible without the kind help of Prof. Talledo, from University of Venice, who compiled and shared the necessary OpenSees executable for the analysis.

\section{REFERENCES}

[1] M. Tomaževič, Earthquake-Resistant Design of Masonry Buildings, Imperial College Press, London, UK, 1999. https://doi.org/10.1142/9781848160835.

[2] J. Bothara, S. Brzev, A Tutorial: Improving the Seismic Performance of Stone Masonry Buildings, First Edit, Earthquake Engineering Research Institute, Oakland, California, 
United States of America, 2011.

[3] J. Ortega, G. Vasconcelos, H. Rodrigues, M. Correia, Assessment of the influence of horizontal diaphragms on the seismic performance of vernacular buildings, Bull. Earthq. Eng. (2018). https://doi.org/10.1007/s10518-018-0318-8.

[4] J. Scacco, N. Bianchini, N. Mendes, C. Cullimore, L. Jain, Seismic assessment of the Church of Carmo Convent, Congr. Métodos Numéricos Em Eng. (2019).

[5] I.E. Senaldi, G. Magenes, A. Penna, A. Galasco, M. Rota, The effect of stiffened floor and roof diaphragms on the experimental seismic response of a full-scale unreinforced stone masonry building, J. Earthq. Eng. 18 (2014) 407-443. https://doi.org/10.1080/13632469.2013.876946.

[6] B. Pantò, F. Cannizzaro, S. Caddemi, I. Caliò, 3D macro-element modelling approach for seismic assessment of historical masonry churches, Adv. Eng. Softw. 97 (2016) 4059. https://doi.org/10.1016/j.advengsoft.2016.02.009.

[7] C. Casapulla, A. Maione, L.U. Argiento, Seismic analysis of an existing masonry building according to the multi-level approach of the italian guidelines on cultural heritage, Ing. Sismica. 34 (2017) 40-59.

[8] C. Casapulla, L.U. Argiento, Non-Linear Kinematic Analysis of Masonry Walls Out-ofPlane Loaded. the Comparative Role of Friction Between Interlocked Walls, Proc. 6th Int. Conf. Comput. Methods Struct. Dyn. Earthq. Eng. (COMPDYN 2015). (2017) 23012311. https://doi.org/10.7712/120117.5568.18332.

[9] Italian Ministry of Infrastructure and Transport, NTC 2018 - D.M. 17.01.18: Aggiornamento delle "Norme Tecniche per le costruzioni," (2018) 1-198.

[10] C. Casapulla, L. Cascini, F. Portioli, R. Landolfo, 3D macro and micro-block models for limit analysis of out-of-plane loaded masonry walls with non-associative Coulomb friction, Meccanica. 49 (2014) 1653-1678. https://doi.org/10.1007/s11012-014-9943-8.

[11] O. AlShawa, D. Liberatore, L. Sorrentino, Dynamic One-Sided Out-Of-Plane Behavior of Unreinforced-Masonry Wall Restrained by Elasto-Plastic Tie-Rods, Int. J. Archit. Herit. 00 (2019) 1-18. https://doi.org/10.1080/15583058.2018.1563226.

[12] L. Giresini, M. Fragiacomo, M. Sassu, Rocking analysis of masonry walls interacting with roofs, Eng. Struct. 116 (2016) 107-120.

[13] F. Solarino, D. V Oliveira, L. Giresini, Wall-to-horizontal diaphragm connections in historical buildings: a state-of-the-art review, Eng. Struct. (2019).

[14] S.M.T. Moreira, Seismic retrofit of masonry-to-timber connections in historical constructions, Universidade do Minho, 2015.

[15] M. Collins, B. Kasal, P. Paevere, G.C. Foliente, Three-dimensional model of light frame wood buildings. II: Experimental investigation and validation of analytical model, J. Struct. Eng. 131 (2005) 684-692. https://doi.org/10.1061/(ASCE)07339445(2005)131:4(684).

[16] G. Rinaldin, C. Amadio, M. Fragiacomo, A component approach for the hysteretic behaviour of connections in cross-laminated wooden structures, Earthq. Eng. Struct. Dyn. 42 (2013) 2023-2042. https://doi.org/10.1002/eqe.2310.

[17] H. Isoda, S. Tesfamariam, Connections for Timber-Concrete Hybrid Building: Experimental and Numerical Model Results, J. Perform. Constr. Facil. 30 (2016) 04016024. https://doi.org/10.1061/(asce)cf.1943-5509.0000849.

[18] American Society of Civil Engineers (ASCE), ASCE/SEI 41-13 : Seismic evaluation and 
retrofit of existing buildings, 2013.

[19] EN 1998-3, Eurocode 8: Design of structures for earthquake resistance - Part 3: Assessment and retrofitting of buildings, 2005.

[20] American Society of Civil Engineers (ASCE), Structural Engineering Institute (SEI), ASCE/SEI 41-17 Seismic Evaluation and Retrofit of Existing Buildings, American Society of Civil Engineers, Reston, Virginia, 2017. https://doi.org/10.1061/9780784414859.

[21] G.L. Fenves, ZeroLength Element, Univ. Texas, Austin. (2014). https://opensees.berkeley.edu/wiki/index.php/ZeroLength_Element (accessed January 20, 2020).

[22] F. McKenna, G.L. Fenves, F.C. Filippou, M. Scott, Open system for earthquake engineering simulation (OpenSees), (2000). http://opensees.berkeley.edu.

[23] K. Bayer, I. Tomic, A. Penna, M. Dejong, C. Butenweg, SERA Project: Seismic Testing of Adjacent Interacting Masonry Structures (AIMS), (2019). http://sera-aims.com/.

[24] R. Faria, J. Oliver, M. Cervera, A strain-based plastic viscous-damage model for massive concrete structures, Int. J. Solids Struct. (1998). https://doi.org/10.1016/S00207683(97)00119-4.

[25] E. Arash, E. Zaghi, M. Cashany, ZeroLengthImpact3D, Univ. Connect. (2014). https://opensees.berkeley.edu/wiki/index.php/ZeroLengthImpact3D (accessed January 20, 2020).

[26] C. Casapulla, F. Portioli, Experimental tests on the limit states of dry-jointed tuff blocks, Mater. Struct. Constr. 49 (2016) 751-767. https://doi.org/10.1617/s11527-015-0536-3.

[27] G. Vasconcelos, P.B. Lourenço, D. Oliveira, Experimental shear behavior of stone masonry joints, in: Struct. Anal. Hist. Constr. Preserv. Saf. Significance - Proc. 6th Int. Conf. Struct. Anal. Hist. Constr. SAHC08, 2008. https://doi.org/10.1201/9781439828229.ch87.

[28] P.B. Lourenço, L.F. Ramos, Characterization of cyclic behavior of dry masonry joints, J. Struct. Eng. (2004). https://doi.org/10.1061/(ASCE)0733-9445(2004)130:5(779).

[29] A.K. Chopra, Dynamics of Structures 4th Edition, 2019. https://doi.org/10.1017/CBO9781107415324.004.

[30] L. Luzi, R. Puglia, E. Russo, M.D. Amico, G. Lanzano, F. Pacor, C. Felicetta, Engineering Strong-Motion database : a gateway to access European strong motion data, 16th World Conf. Earthq. Eng. Santiago, Chile, 9-13 January. 899 (2017). 